\title{
MITIGATING CONTRACTOR PROBLEMS EXPERIENCED IN THE CONSTRUCTION INDUSTRY OF TRINIDAD \& TOBAGO
}

\author{
Derek Outridge ${ }^{1 *}$ and Roshan Patel $^{2}$ \\ ${ }^{1,2}$ Faculty of Engineering, The University of the West Indies, Trinidad \\ ${ }^{1}$ Email: derek.outridge@ sta.uwi.edu* \\ ${ }^{2}$ Email: roshan.patel176@gmail.com
}

\begin{abstract}
The construction industry of Trinidad and Tobago has been, for decades, a direct indicator of national development and contributor to economic growth. The associated problems of the industry as experienced by contractors negatively impacts project performance and success. This study identified the most common problems experienced by contractors and assessed these to determine their level of significance and importance to projects. Employing a survey questionnaire and analytical methods using the Statistical Package for the Social Sciences (SPSS), 43 problems were identified, classified into seven (7) factor groups: Financial, Managerial, Environmental, Labour Based, Resource Based Owner Based and Project Based that were ranked on their level of significance and importance. The top ten (10) problems were found to be delay of payments, design, scope and material changes, working in high risk areas, lack of feasibility and brief, corruption, lack of contractor's experience, bureaucracy, geological problems, contractor's finances and cash flow. These problems represent the Financial, Managerial, Environmental, Project Based and Owner Based factor groups with financial factors being the highest rated group of adverse effect and significance. Highlighting the findings of this study, the preferred solution to mitigate against the adverse impact indicative of the construction problems experienced were presented. These solutions can be implemented to reduce the adverse effects on projects, promoting sustainable construction practices in the construction industry of Trinidad \& Tobago.
\end{abstract}

Keywords: Construction industry, Construction problems, Contractor problems, Project overruns, Project irregularities.

https://doi.org/10.47412/CEKP4197

\section{Introduction}

This research analysed the problems experienced in the Trinidad \& Tobago's public sector construction industry and prioritized these as to their adverse impact. There have been many projects which exhibited cost overruns due to inflation, inadequate planning, poor management \& design leading to design changes, insufficient preliminary investigation, over ambiguous objectives and litigation problems. Their consequences deprive the local population of, value for tax- payer's money, high standards, and specification of works performed, transparency and integrity, free and fair competition for local and foreign contractors [13].

In 2013, at the Trinidad \& Tobago Local Content Workshop, "Local Construction: Boom or Doom, ” Professor Clement Sankat, highlighted that the local Construction Industry was extremely 
important to the economy [3]; and according to the Trinidad \& Tobago Investment Guide 2011/2012, construction accounts for $7.1 \%$ of the country's GDP and employs $16.4 \%$ of its labour force. The Industry is therefore of critical importance as thousands of people are directly and indirectly affected by its performance, irrespective of the country's economic growth or decline [6]. A study conducted at the National University of Singapore, highlighted that the construction industry in many countries faced problems and challenges. In the developing countries, these difficulties exist additionally alongside a general situation of socio-economic stress, chronic resource shortages, institutional weaknesses and a general inability to deal with the key issues facing the countries [8].

This study determined from literature, both locally and internationally, the construction industry problems and prioritize these in respect of their impact to Trinidad \& Tobago's construction sector and made recommendations to resolve or minimize their adverse consequences. By identifying the problems and determining their significance, it was expected that the findings would provide advice to improve the performance of the Trinidad \& Tobago's construction industry. It would also enable the recommendations contained in the 2010, "Report of the Commission of Enquiry, into the Construction Sector of Trinidad and Tobago," (The Uff Report), to be systematically and strategically implemented. Challenges have always plagued the global construction industry and there have been many scholarly studies in respect of its problems, by way of details of investigations into the success and failures of projects or, by virtue of commissions of enquiries into the construction industries of several countries such as, the United Kingdom [4] [10] [15], Taiwan [16], Turkey [2], the USA [14] and many more; their construction industries show similar problems to those identified in The Uff Report [13]. These problems became significant in the local context, during the construction boom of the late 1970's to early 1980's as such, they were analysed to ensure preventative actions be taken. These construction problems were determined to be caused from changes in scope, delay of payments, inflation, lack of expertise and many more as are identified in this paper.

\subsection{Problem Statement}

The construction industry is considered as the economic barometer of a country and if there are adverse consequences existing within it, this will ultimately affect the country's development. The lack of pride and moral approaches for completed construction works were of growing concern among local contractors whereby projects were widely seen as unpredictable in terms of, delivery on time, within budget, to the standards of quality and specification. Construction projects often failed to meet the needs of modern businesses that must be competitive in international markets, and rarely provided best value for clients and taxpayers [10]. These construction sector problems identified in The Uff Report inflicted large deficits on a country's budgets and as a result caused unnecessary spending thus depleting government treasuries and burdening taxpayer pockets.

\subsection{Research Aim and Objectives}

\subsubsection{Aim}

To identify and prioritize problems experienced by contractors in Trinidad \& Tobago's construction industry. 


\section{With the prevalent economic impacts identified and aim established, the objectives of the} study are:

1) To determine the problems in the global construction industry

2) To determine the problems within the Trinidad \& Tobago construction industry

3) To assess and prioritize the significant problems experienced by Trinidad \& Tobago small and medium, and large contractors.

4) To recommend solutions to negate any adverse effects of the significant problems in the Trinidad \& Tobago construction industry

\subsubsection{Rationale and Hypothesis}

The problems experienced by contractors undertaking construction projects in Trinidad \& Tobago are similar to those experienced in the construction industries of other countries. The Uff Report identified a list of problems and causes experienced within Trinidad \& Tobago's construction industry but made no attempt to determine their significance i.e. their frequency and/or severity of their adverse impacts. Without this priority perspective, the Trinidad \& Tobago's construction industry nor its stakeholders would be able to eliminate or reduce any of their negative consequences in an efficient and effective manner. Any attempt to resolve these problems without determining if there is a difference in significance of impact to the local construction industry could give rise to greater negative or possibly disastrous consequences to industry contractors, stakeholders and the society at large.

Therefore, the Hypothesis proposed was:

The problems experienced in the Trinidad \& Tobago construction industry, are of equal significance, irrespective of contractor size.

\section{Literature Review}

Based on the relevant information, the research related to the types of problems experienced in the construction sector, literature was analysed, evaluated and selected. As mentioned, in Trinidad \& Tobago The Uff Report is the latest source of information given it investigated projects done by state agencies of Trinidad \& Tobago such as the Urban Development Corporation of Trinidad and Tobago Limited (UDeCOTT), Housing Development Company (HDC), Estate Management and Business Development Company (EMBD) and many more [13]. Problems such as corruption, wrong types of contract procurement, inadequate and incompetent labour, design changes and flaws, quality and value for money, have been the source of project failures, which led to the commissioning of this Report. The plethora of problems identified within the construction industry are not isolated to Trinidad \& Tobago alone; it is in fact a phenomenon that exists as identified by enquiries in the construction industries of many countries such as the United Kingdom [4], Taiwan [16], Turkey [2], the USA [14], India [5], The United Arab Emirates [7], Korea [11] and The Organization of Eastern Caribbean States (OECS) [9]. Information was sourced from these countries through journals, reports, opinions and studies that were collected and analysed to formalize the Literature Review of this study. Relevance was based upon similarities of problems identified in The Uff Report [13]. This determination of the more significant existing global problems provides a basis to analysing which problems should be prioritized for resolution, and 
ensuring efficiency when planning and designing projects that will in long run add to project success.

\subsection{A Global Perspective}

In Turkey, Kazaz, Ulubeyli, \& Tuncbilekli, identified problems which caused projects to spiral into delays and cost overruns and determined their importance. Seven groups were used to collect data and were categorized as follows: Environmental, Financial, Labour-based, Managerial, Owner based, Project-based, Resource-based factors. Financial factors and labour-based factors were found to be the first two groups while the least effective one was the group of environmental factors [2]. Lee, also investigated cost overruns and delays in Korean Social Overhead Capital Projects such as roads, rails, airports and ports. Using data from 161 completed projects he weighed estimated costs of projects against actual costs and effects of inflation. Analysis also indicated delays in projects were caused as a result of scope changes. In summary factors such as concept changes, environment, costs and other changes which inflicted delays and concluded changes in scope of a project, delays in construction, unreasonable estimations and adjustment of project costs, and no practical use of the earned value management systems were the dominant causes of problems in the Korean transportation construction industry [11].

KPMG produced articles on project success and failures such as "The Great Global Infrastructure Opportunity" and "Avoiding Major Project Failure - Turning Black Swans White". These articles were globally focused on several problems experienced in construction sectors relating to opportunities, threats, performance, expectations, efficiency and risk management [14]. Proverbs produced "Construction Industry Problems: The Views of UK Construction Directors", which relayed the myriad of problems encountered in the UK construction sector and found that clients were generally dissatisfied with the level of service and quality of the end-product [4]. Two significant studies in the UK industry have been from the Reports of Latham [15] and Egan [10] were the hallmarks of the revolutionary solutions for the UK construction industry.

- The Latham Report: In the United Kingdom the Latham Report (1994) signified a transformation for the UK construction industry, radically transforming relationships between contractors \& clients. Latham identified the industry's inefficiencies, condemning existing industry practices as adversarial, ineffective, fragmented, incapable of delivering for its clients' and "Lacking respect for its employees". A key concept was that through teamwork the construction industry could satisfy its customers and he made 53 recommendations based on these concepts; in order to replace the bureaucratic, wasteful and adversarial atmosphere prevalent in most construction projects with one characterised by openness, co-operation, trust, honesty, commitment and mutual understanding among team members [15].

- The Egan Report: Outlined in this report the United Kingdom construction industry had severe problems relating to quality, skilled and competent contractors, and made recommendations for contractors to provide value for money and procedures for mitigation adverse consequences of identified problems. The Construction Task Force was commissioned by the Deputy Prime Minister and led by Sir John Eagan which found that a large amount of the industry investor's complained of low productivity which required improvements in to its quality and to enhance performance. Methods of improvement were 
suggested by a Task Force of experts from different industries with enhanced systems and processes that improved sustainability. The Task Force identified five key drivers of change management, committed leadership, focus on the customer, integrated processes and teams, quality driven agenda and commitment to people. Integrated systems for project enactment follow four key elements: project implementation, partnering the supply chain, product development and production of components [10].

\subsection{The Regional and Local Construction Industry}

Project journals were acquired from the University of the West Indies for investigation of regional challenges and developments.

- Final OECS Construction Sector Strategy Report - The Peter's Report: A Final Strategy Report was developed by John A. Peters, which identified construction as one of the key sectors in of the OECS Growth and Development Strategy. The construction sector made important contributions, both directly and indirectly, to economic growth and job creation in the OECS. Construction activity exerted positive short-term growth and employment thus generating effects within and outside of the sector, which can be significantly enhanced by increasing the speed and efficiency of the construction process itself. The sector had positive long-term growth impacts, by virtue of enhancing the supply capacity of the economy and the competitiveness of productive sectors that utilize the infrastructure or physical capital created by construction activity. The report presented a series of recommendations which were segmented into 18 immediate implementations and 7 medium term implementations to reduce the effects of impediments faced. [9].

- The Uff Report: On the 29th of March 2010 the Report of the Commission of Enquiry into the Construction Sector of Trinidad \& Tobago was submitted to the President of the Republic of Trinidad \& Tobago by the Chairman of the commissioners, Professor John Uff. The purpose of the commission of enquiry was to investigate and make recommendations into public projects in the construction sector of Trinidad \& Tobago. Considering the challenges faced, ninety-one recommendations were made pertaining to the construction sector as a whole. Given that:

a) Value for taxpayer's monies required that irregularities be avoided; projects to be undertaken in a justifiable manner to ensure monies are spent efficiently to provide a high level of service of the product or project being generated.

b) Appropriate standards were noted that is renowned for its ease and adaptability for users.

c) There was economic justification for protecting the local construction sector, however, the provision of a quota or subsidy in favour of local contractors and consultants as against foreign competition was not supported [13]. 
d) Corruption was found to be developing, and methods were to be put in place to mitigate against unlawful practices.

From the review of reports and literature, common problems identified in the construction industry were identified below.

1. Legal and Regulatory Requirements

2. Financing of Project

3. Procurement Practices and Procedures

4. Project Planning

5. Payment

6. Materials Quality and Supply

7. Workforce Availability and Training

8. Fragmentation

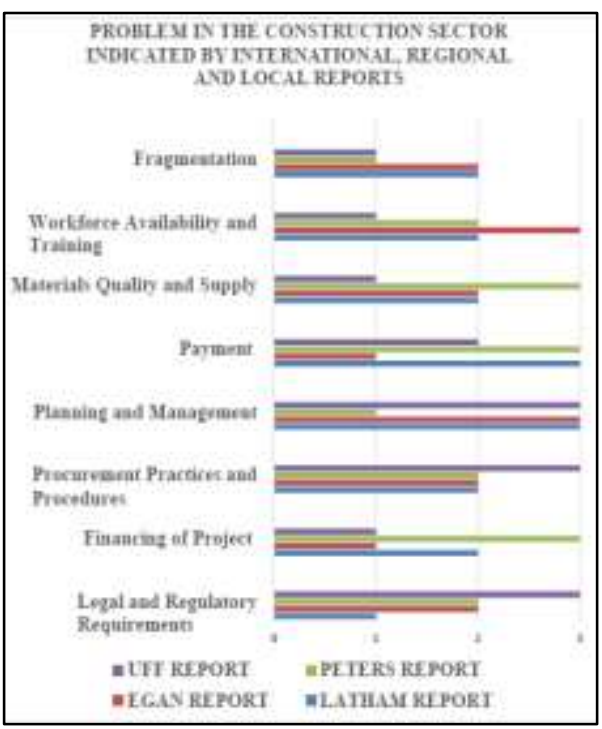

9. Foreign vs. Local Contractors and Consultants

Chart (1) displays the frequency rank of the problems as indicated by the reviews. Where: Minor Problem $=1$,

Moderate Problem = 2, Major Problem $=3$.

\section{Chart 1: Shows Frequency Ranking of Common Problems in the Construction Industry}

The literature review illustrated a hollistic view of the scale of construction industry problems experienced in several countries including Trinidad and Tobago. These construction industry problems were categorised in seven (7) groups and a total of forty-three (43) problems were compiled as shown in Table 2 below. This compilation was guided by several reasearch findings and reports such as, The UFF (2010) Report, which guided this study. In the Trinidad and Tobago context, UFF identified the construction industry problems, but they were not categorized and ranked to show their importance. This research seeks to demonstrate these problems and their significance as they relate to small and medium, and large contractors.

\section{Methodology}

The research structure of this study adopted a quantitative methodological approach. This was selected as the study sought to determine the contractor problems impacting the local construction industry (independent variable) and prioritize these problems (dependent variable). Primary data was gathered using a population sample selected via a descriptive study where associations between the variables were subsequently established and empirical data evaluated. In order to achieve the objectives of this study, the following procedures were followed:

1. Statistics found in the Uff Report were examined to determine the importance of the construction industry to the local economy and the occurrence of local construction problems.

2. Comprising existent international and local studies that were examined to assist in identifying the local construction problems related to research based in the literature review. These studies were used to form the foundation for problem factors utilized in this study's research questionnaire. 
3. Based on the similarities of the research, three studies on construction problems were critiqued to form the basis for comparison within the discussion section.

4. In order to gather accurate information, it was of high importance that the respondents be provided with a background of the research being conducted, inclusive of the purpose of the study and clear instructions regarding the requirements for their participation.

5. The questionnaire asked respondents to prioritize the problems by selecting the box coinciding with the level of importance they placed on each problem presented.

6. This information was subsequently used to determine the Relative Importance Indices (RII) which in turn enabled the ranking of the problems as to importance.

7. Conclusions were formulated based on these discussions and recommendations for further study were made.

\subsection{Research Design and Analysis}

According to Sung-Yul research design can be described as a holistic plan chosen by the researcher to incorporate the various components of the study in a rational and logical manner, thereby ensuring the research problem is addressed effectively. Eventfully before the type of method of research was chosen the following factors were considered: Ease and availability of collection of opinions and time to achieve the information accurately to ensure quality and total number of samples to be acquired to ensure a valid cost and time to acquire data [11].

\subsection{Data Collection Procedure}

The collection of data took place between the months December 2015 to March 2016. The sample population was determined by systematic sampling. First, contractors involved in the local construction industry were identified and permission for employees to participate in this research obtained from the head of each company. After confirming permission to participate, the questionnaire was distributed via electronic mail and in some instances hand delivered. Responses were collected within four months of distribution. A total of one hundred questionnaires were distributed, 75 responses were received with large, medium and small contractors having the representative 25 respondents each. The data collected was further analysed to determine any trends and patterns that may exist using Pearson's correlation and regression analysis.

\subsection{Analytical Approach}

In the United Arab Emirates (UAE) construction industry Megha and Rajiv based their Relative Importance Index (RII) from the perspective of the construction industry's main participants, contractors and consultants and used the RII to identify and rank the significant causes of delay [7]. The RII was computed to rank the importance of the different factors in the questionnaire.

Where: $\mathrm{W} i=$ the weighting assigned to $i$ th response; $\mathrm{W} i=5,4,3,2,1$ and 0 for $i=1,2,3,4$ and 5 respectively.

$$
\mathrm{RII}=\frac{\sum_{i=1}^{5} W i X i}{\sum_{i=1}^{5} X i}
$$


Kish's formula was also used to calculate the sample size using the following equation for $95 \%$ confidence level [1]:

$$
\mathbf{n}=\mathbf{n}^{1} /\left[1+\left(\mathbf{n}^{1} / \mathbf{N}\right)\right]
$$

A total of forty-three (43) problems were identified as the major problems and utilized. These incorporated construction problems obtained from the literature review. Kazaz, Ulubeyli, and Tuncbilekli (2011) grouped these problems into seven categories being: Financial, Environmental, Managerial, Labour, Resource, Owner and Project and determined a Resultant Index Interval (Table 1). For the analysis of the data the RII was calculated using Eq (1).

Table 1: Resultant Index Interval [2]

\begin{tabular}{|l|l|l|l|l|}
\hline Not & Somewhat & & Very & Extremely \\
$1.00-1.80$ & $1.81-2.60$ & $2.61-3.40$ & $3.41-4.20$ & $4.21-5.00$ \\
\hline
\end{tabular}

Pearson product-moment correlation coefficient was calculated to determine accuracy, using:

$$
r=r_{x y}=\frac{n \sum x_{i} y_{i}-\sum x_{i} \sum y_{i}}{\sqrt{n \sum x_{i}^{2}-\left(\sum x_{i}\right)^{2}} \sqrt{n \sum y_{i}^{2}-\left(\sum y_{i}\right)^{2}}}
$$

Where:

- $\mathrm{n}$ - represents the number of pairs of data collected

- $\quad \sum$ - denotes the addition of the items indicated

- $\sum \mathrm{x}$-denotes the sum of all $\mathrm{x}$ values

- $\sum x^{2}$ - indicates that each $x$ value should be squared and then those squares added

- $\left(\sum x^{2}\right)$ - indicates that the $x$ values should be added and the total then squared

- $\quad \sum x y-$ indicates that each $\mathrm{x}$ value should first be multiplied by its corresponding $\mathrm{y}$ value after obtaining all such products, find their sum.

- r- represents the linear correlation coefficient for sample

- $\mathrm{p}$ - represents the linear correlation coefficient for the population 


\section{Summary Research Findings}

Table 2: Raking of problems in construction industry

\begin{tabular}{|c|c|c|c|c|}
\hline Problem: & Rating & $\begin{array}{l}\text { Resultant Index } \\
\text { Interval }\end{array}$ & $\begin{array}{l}\text { Importance } \\
\text { Letel }\end{array}$ & $\begin{array}{l}\text { Factar } \\
\text { Group }\end{array}$ \\
\hline Delay of pormeds & 1 & 4,75 & Extremely Imp & Fimantral \\
\hline Dectipg woro \& material chanret & 2 & 4.37 & Frtremely Imp & Monarerial \\
\hline Iigh risk areas & 3 & 4.20 & Vers Imp & Empoonneptal \\
\hline ack of fesoibility and brief & 4 & 4.17 & Ver $\ln p$ & Project Baned \\
\hline Comuptios & 5 & 4.02 & Ven liap & Froser Bived \\
\hline 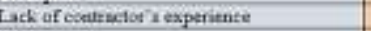 & 6 & 3.91 & Ver limp & Mlatageral \\
\hline Buteautracy. & 7 & 3.85 & Ver limp & Oumnt tasid \\
\hline Beakreal problems & 8 & 3.82 & Very imp & Enitamentibl \\
\hline Contracturn finantrial problin= & 9 & 3.80 & Very Imp & Financial \\
\hline Casls tow problema & 10 & 3.20 & Ver $\operatorname{limp}$ & Finatecial \\
\hline Poor rite sathagement. & 11 & 3.80 & Very lape & Mingyaral \\
\hline Woik sersidents & 12 & 3.78 & Veny Imp & Emurutuatatuf \\
\hline Chavge in ronermment & 13 & 3.77 & Ver Imp & Exwirongetutel \\
\hline Mroos type of procurement & 14 & 3.77 & Ver Inep & Mreaperial \\
\hline Conissuctise defocts & 15 & 3.74 & Verg $\operatorname{lmp}$ & Labour Based \\
\hline Advene weatber csaditious & 16 & 3.74 & Ven $\operatorname{lmp}$ & Exhiratnestul \\
\hline Porar qualis coelsal & 17 & 3.72 & Yet luxp & Afmageral \\
\hline Katuguement Faults & 18 & 3.68 & Verr Imp & Oemat taseat \\
\hline $\begin{array}{l}\text { Poor mainteosnce of works, materisls and } \\
\text { equipmeat }\end{array}$ & 19 & 3.62 & Ver Imp & Prosect Baved \\
\hline Poat tesoutce poductivity & 20 & 3.60 & Very Intp & Feprate fisud \\
\hline Poor labour pentactivity & 21 & 3.57 & Ven Iimp & Lwhour ilased \\
\hline Poor moterial management & 22 & 3.54 & Ver $\lim p$ & 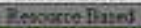 \\
\hline and acquiaition & 23 & 3.54 & Ver Imp & Envoroments \\
\hline Projact scale(rite) & 24 & 3.54 & Very lisp & Thogect Brasd \\
\hline Extimation problems & 25 & 3.51 & Vers Imp & Aresperisal \\
\hline Contract relased dispurea & 26 & 3.40 & Very lisp & Manageral \\
\hline Foor coordination between parties co arte & 27 & 3,49 & Very imp & Menaptial \\
\hline Dic imbiguau objectives & 28 & 3.47 & Very lapp & Ginturt fined \\
\hline Mamazes minker relubicen & 20 & 3.45 & Very linp & Managaral \\
\hline hontape of nkilled worken & 30 & 3.40 & Important & Lahour Based \\
\hline Luctowtion it materint prices & 31 & 3.40 & Important & Financial \\
\hline $\begin{array}{l}\text { Iflaticn } \\
\text { Improper Material Selection }\end{array}$ & 34 & $\begin{array}{l}3.38 \\
3.35\end{array}$ & $\begin{array}{l}\text { Timonrant } \\
\text { Important }\end{array}$ & $\begin{array}{c}\text { Finmerial } \\
\text { Resource Based }\end{array}$ \\
\hline Conflict between parties onsite & 35 & 3.32 & Important & Managerial \\
\hline Rarely used construction methods & 36 & 3.23 & Important & Project Based \\
\hline Contractor's excessive workload & 37 & 3.14 & Important & Managerial \\
\hline Site Location and layout & 38 & 3.06 & Important & Environmental \\
\hline Old construction methods & 39 & 3.03 & Important & Project Based \\
\hline Material storage problems (owner based) & 40 & 3.03 & Important & Owner Based \\
\hline $\begin{array}{l}\text { Transportation problems of resources (owner } \\
\text { based) }\end{array}$ & 41 & 2.92 & Important & Owner Based \\
\hline $\begin{array}{l}\text { Transportation problems of resources } \\
\text { (resource based) }\end{array}$ & 42 & 2.88 & Important & Resource Based \\
\hline Material storage problems (resource based) & 43 & 2.78 & Important & Resource Based \\
\hline
\end{tabular}

Table 2, depicts all the forty-three (43) problems listed in descending order with all factor groups Financial, Environmental, Managerial, Labour Based, Resource Based, Owner Based and Project Based associated. It also shows the importance indexes of all problems in descending order and the importance classification. All factors displayed have an importance level from extremely important to important with no problems being classified as not important. It can be said that all problems have a crucial part to play in the roles and life cycle of a project from the initial to close out stage. Problems were also ranked in descending order and importance based on the literature acquired. Table 2, also demonstrates that in the top ten ranked problems. For the Factor Groups, Financial, there were three problems; Managerial, Project Based and Environmental, there were two problems each; and Owner Based there was one problem. There were no Labour Based or Resource Based problems in the top listing. 
Table 3: Severity index

\begin{tabular}{|c|c|c|c|c|}
\hline \multirow{2}{*}{ Rank } & Problems & LARGE & MIEDIUM & SMALL \\
\cline { 3 - 5 } & & \multicolumn{3}{|c|}{ Severity \% } \\
\hline 1 & Delay of payments & 95.24 & 96.00 & 92.05 \\
\hline 2 & $\begin{array}{c}\text { Design, scope \& material } \\
\text { changes }\end{array}$ & 72.00 & 67.27 & 63.48 \\
\hline 3 & High risk areas & 59.05 & 67.83 & 49.57 \\
\hline 4 & $\begin{array}{c}\text { Lack of feasibility and } \\
\text { brief }\end{array}$ & 65.71 & 63.64 & 62.61 \\
\hline 5 & $\quad \begin{array}{c}\text { Corruption } \\
\text { experience }\end{array}$ & 65.71 & 63.81 & 53.00 \\
\hline 7 & $\begin{array}{c}\text { Lack of contractor's } \\
\text { Bureaucracy }\end{array}$ & 53.33 & 66.36 & 55.00 \\
\hline 8 & Geological problems & 60.95 & 58.18 & 46.09 \\
\hline 9 & $\begin{array}{c}\text { Contractors financial } \\
\text { problems }\end{array}$ & 56.19 & 59.09 & 53.78 \\
\hline 10 & Cash flow problems & 60.95 & 55.45 & 50.91 \\
\hline \multicolumn{4}{|c|}{} \\
\hline
\end{tabular}

Table 3, depicts the severity index of the first ten ranked problems in order of importance as compared to different contractor sizes. For "Delay of payments" all issues fall in the ninetypercentile range. The analysis identified that the most affected categories were medium and large contractors.

All the data collected were analysed using statistical methods and described using charts and tables associated with the top ranked problems. Forty-three (43) problems were outlined, means calculated and represented in descending order which gave a ranking of their significance. The top ten problems were further analysed by comparing them against the respondents from small, medium and large contractors. These ten problems were also analysed and compared against the views of directors, project managers, consultants, engineers and site managers who comprised the respondents to the study. The severity of these top ten problems affecting small, medium and large contactors were calculated and percentages shown.

Two ANOVA one-way tests were conducted to calculate the significance of the problems to all contractor sizes and to test if they were of equal significance to each other. The two hypothesis statements tested were the null hypothesis, $\mathrm{HO}$, and the other being another option, H1. They are as follows:

HO: The problems experienced in Trinidad \& Tobago's construction industry are of equal significance, irrespective of the contractor size.

H1: The problems experienced in Trinidad \& Tobago's construction industry, are not considered to be of equal significance, irrespective of the contractor size.

It was concluded from the ANOVA tests performed, of the forty-three (43) problems, 75\% of problems mentioned, have a $\mathrm{P}$ value $>0.05$ and for the other $25 \% \mathrm{~F}$ values $>1$, which shows that all problems listed affected all contractors, indicative of their size. Further means were calculated using the $\mathrm{F}$ statistic comparison which showed that all values were considerably greater than 1 $(\mathrm{F}>1)$ which can be stated to reject $\mathrm{HO}$ and do not reject $\mathrm{H} 1$, concluding that the problems are not considered to be of equal significance. Mitigation methods were suggested for all forty-three (43) problems. 


\section{Conclusion}

The aim of this research was to determine, identify and prioritize the major problems experienced in Trinidad \& Tobago's construction industry. These were pursued by specific objectives and are outlined as follows:

Objective $1 \&$ 2: To determine problems within global construction industries and Trinidad \& Tobago's construction industry. Through review of literature based locally, regionally and internationally the factors that contribute to such problems were identified.

Comparisons show that between international construction industry reports and the local Uff Report along with responses from the locally administered questionnaire survey, it was found that the Trinidad and Tobago's construction industry has similar problems as those in the global context. Some of these major contractor problems were outlined to be delayed payments, incomplete design, scope creep and material changes, working in high risk areas, lack of a brief and feasibility studies, irregularities and corruption.

Objective 3: To determine and prioritize the significance of the problems experienced by the Trinidad \& Tobago's small, medium and large contractors.

In reference to the data acquisition and data analysis outlined, forty-three (43) problems were outlined and ranked according to their importance. As compared to global problems such as design, scope and material changes which were found from other studies to be their highest ranked problem, T\&T's number one ranked problem is seen as delayed payments. On the global scale delayed payments was the second most significant problem. Many contractor problems were found to fall within the financial, managerial and environmental factor groups. Financial factor problems of delayed payments was the highest ranked problem and directly affects the general economic state of a country. Many managerial factor problems arise due to hasty decisions by clients to commence projects without, proper planning, preliminary investigations and scope definitions. Issues also arose due to environmental factors such as working in high risk areas where contractors must pay communities to perform works.

For objective 2, the two hypothesis statements were tested, it was concluded from the ANOVA tests performed to the forty-three (43) problems, $75 \%$ of problems mentioned, have a $\mathrm{P}$ value > 0.05 and for the other $25 \% \mathrm{~F}$ values $>1$, which shows that all problems listed affect all contractors, indicative of their size. Further means were calculated using the F statistic comparison which showed that all values were considerably greater than $1(\mathrm{~F}>1)$ which can be stated to reject HO and do not reject $\mathrm{H} 1$, concluding that the problems are not considered to be of equal significance.

Objective 4: To recommend solutions to negate the effects of these significant problems in Trinidad \& Tobago's construction industry.

In the top ten ranked problems, it was shown that delay of payments was the number one problem requiring remedy as displayed in the financial grouping of problems. This being a major issue experienced with all levels of contractors has a severe impact and a domino effect to other problems. These problems are contractors' financial and cash flow problems. Also indicated in results, the two major positions held by directors and project managers have the most issues. 
Managerial factors such as design, scope and material changes which from the study is shown to be the second highest ranked problem experienced. Many companies in the energy sector have adopted the approach of using strategies such as design freeze whereby no changes are made during the project, but a new project is initiated to make changes. Another managerial problem was ranked at number 6 , being a lack of contractor experience. The third ranked problem was an environmental one, high risk areas where contractors in these communities insist they must be paid before work is commenced and contractors will perform works in these areas at increased rates which make the associated projects costlier.

Another environmental problem was projects being undertaken in the domain of expansive clays located especially in the southern region of Trinidad. Many projects are stopped and spiral into overruns caused by insufficient and inadequate designs due to Geological problems which is ranked at number 8 . It is clearly seen that many problems stem from each other as mentioned above. Geological problems which is an environmental factor is linked with a lack of feasibility and design brief being performed which is a project-based factor. This specific problem is ranked at number 4, has plagued the local industry to this date. Many projects fail before they even start as a result of this problem. These contractor problems should be addressed by the independent agencies many of which comprise the Joint Consultative Council for the Construction Industry (JCCCI) which should incorporate a proactive role into the award of contracts and examination on types of procurement methods chosen. In the past and present, the construction industry both locally and internationally suffer from owner-based problems such as bureaucracy which is ranked number 7 and management faults, ranked at number 13, and are considered significant issues by most contractors and clients to date. If responsibility and communication gaps are bridged and employees of utility companies and consultants are held accountable for their errors, many of these problems can easily be mitigated.

In conclusion, the two factor groups which have lower significance in this study such as Labour based problems and Resource based problems incorporated low productivity and quality issues should be mitigated against by contactors work and monitoring systems implied by clients. These problems have all been categorized, ranked and their significance calculated which require more detailed research. This study can be exhibited for students in the future as the "Stepping-stone" for further analysis of each problem by conducting more complex and detailed research.

\subsection{Limitations}

Data collection was carried out between December 2015 and March 2016, which proved to be limited time to collect sample data. All contractors are limited to Trinidad \& Tobago and opinions generated were classed from directors, project managers, engineers, consultants and site managers. Due to the significance of these problems existing in our construction industry the research problem is undoubtedly a challenging one and its nature affects all projects and contractor sizes. 


\section{References}

[1]Assaf, Sadi A, and Sadiq Al-Hejji. 2006. "Causes of Delay in Large Construction Projects." International Journal of Project Management 349-357.

[2] A. Kazaz, S. Ulubeyli, and A. N. Tuncbilekli. 2011. Causes of Delays in Construction Projects in Turkey. Journal of Civil Engineering and Management Vol. 18(3), 426-435.

[3] C. Sankat. 2013. Local Construction: Boom or Doom. Trinidad \& Tobago Local Content Chamber Workshop.http://sta.uwi.edu/principal/documents/TTLCCWorkshopLocalConstructionBoomorDoom-Final.pdf

[4] D. G Proverbs, G. D. Holt, and H. Y. Cheok. 2000. Construction Industry Problems: The Views of UK Construction Directors. Akintoye, A (ed.), 16th Annual ARCOM Conference. Glasgow Caledonia University. Association of Researchers in Construction Management, Vol. 1, 73-81.

[5] D. Megha and B. Rajiv. 2013, A Methodology for Ranking of Causes of Delays for Residential Construction Projects in India Context. Issued March 2013.

[6] Evolving Technologies and Enterprise Development Company Limited. 2011/2012. A Guide to Investing in Trinidad \& Tobago, 45.

[7] Fardi and El-Sayegh. 2006. Significant Factors Causing Delay in The UAE Construction Industry, 143

[8] G. Ofori. 2000, Challenges of Construction Industries in Developing Countries: Lessons from Various Countries. Department of Building, National University of Singapore. 133.

[9] J. A. Peters. 2013. Final OECS Construction Sector Strategy Report. Unpublished. 2013

[10] J. Egan. 1998. Rethinking Construction: The Report of The Construction Task Force. DTI (URN 98/1095). Construction Task Force, UK.

[11] J.K. Lee. 2008. Cost Overrun and Cause in Korean Social Overhead Capital Projects: Roads, Rails, Airports, and Ports. Journal of Urban Planning and Development. 134:2(59), 0733-9488. doi:.1061(ASCE) 0733-9488(2008)134:2(59)

[12] J. Sung-Yul Park. 2009. The Local Construction of a Global Language: Ideologies of English in South Korea. National University of Singapore, 196.

[13]J. Uff \& D. Thornhill. 2010. Report of The Commission of Enquiry into the Construction Sector Trinidad and Tobago. Trinidad and Tobago: The Government of the Republic of Trinidad and Tobago.

[14] KPMG International. 2013. Avoiding Major Project Failure-Turning Black Swans White, 35.

[15] M. Latham. 1994. Constructing the Team. Final Report of the Government / Industry Review of Procurement and Contractual Arrangements in The UK Construction Industry. HMSO, London.

[16] Yang, Jhy-Bin., and Wei, Pei-Rei. 2010. "Causes of Delay in the Planning and Design Phases for Construction Projects." Journal of Architectural Engineering: June 2010, doi: 10.1061/(ASCE)1076-0431(2010)16:2(80) 